\title{
La institución parroquial católica en el Antiguo Régimen. Propuesta de análisis y estado de la cuestión*
}

\section{The Catholic parish institution in the Ancien Régime. Proposal for analysis and state of the question}

\author{
Ma Soledad Gómez NAVARRo \\ Universidad de Córdoba \\ Hi1gonas@uco.es
}

Fecha de recepción: 03-03-2019

Fecha de aceptación: 05-05-2019

\begin{abstract}
RESUMEN
Este artículo pretende un doble objetivo. Por un lado, presentar la institución parroquial de la España moderna de un modo bastante desapercibido — por no afirmar inédito — en la historiografía especializada cual es explorarla en su doble, genuina y paritaria identidad de parroquia e Iglesia parroquial, esto es, como jurisdicción — primera noción—, y templo propiamente dicho — la segunda— $\mathrm{y}$, en este caso, tanto como compendio de las diferentes instituciones eclesiásticas que alberga en su seno - "institución de instituciones" sería así la Iglesia parroquial—, cuanto en sí misma, pues también es institución, como se verá. En esta perspectiva de análisis asimismo la academia ha reparado muy poco, por no decir nada, lo que supone también evidente contribución de este texto al conocimiento especializado. Por otro lado, analizar la abundante producción científica que avala la conceptualización indicada y que muestra, efectivamente, la novedad de esta aportación. Son sus dos partes, posibles por el seguimiento de una metodología esencialmente cualitativa y comparada, y que abrochan unas reflexiones finales a modo de conclusión.
\end{abstract}

Palabras clave: Parroquia, Historiografía, Estado de la cuestión, Historia Moderna Topónimos: España

Período: siglos XVI-XVIII

\section{ABSTRACT}

This article has a two-fold objective. On the one hand, to present the parish institution of modern Spain in a rather unnoticed way — for not affirming unpublished - in specialized historiography which is to explore it in its double, genuine and parity identity of parish and parochial Church, that

\footnotetext{
* Aportación realizada en el marco del Proyecto CSO2015-68441-C2-2-P (MINECO/FEDER); así como ampliación y actualización de esta elaboración integrada en la memoria de investigación presentada para concurrir a la plaza de Catedrática de Historia Moderna, que obtuve en mayo de 2018.
} 
is, as a jurisdiction - first notion-, and proper temple -the second- and, in this case, as much as a compendium of the different ecclesiastical institutions that it houses in its bosom - "institution of institutions" would be like that the parochial Church-, as in itself, because it is also an institution, as will be seen. In this perspective of analysis also the academy has repaired very little, to say nothing, which is also evident contribution of this text to specialized knowledge. On the other hand, analyze the abundant scientific production that supports the conceptualization indicated and that shows, in effect, the novelty of this contribution. They are its two parts, made possible by the follow-up of an essentially qualitative and comparative methodology, and which fasten some final reflections by way of conclusion.

Key words: Parish, Early Modern History, Historiography, State of the Art

Place names: Spain

Period: XVI-XVIII centuries

\section{INTRODUCCIÓN}

La visión historiográfica más consensuada de la institución parroquial en la España del Antiguo Régimen la ha considerado bien como jurisdicción — parroquia, collación-, bien como templo — Iglesia parroquial_- pero rara vez como suma paritaria de las dos acepciones. Asimismo, rara vez se ha considerado a la Iglesia parroquial como institución en sí misma y, mucho menos, como suma de las varias y muy diferentes instituciones eclesiásticas entre sí que alberga y acoge en su seno —capellanías, obras pías, casillas de curas, obra y fábrica, asociacionismo religioso...-. Como reza su resumen, reparar en la existencia de ambas dimensiones conjuntamente —como parroquia, entidad por cierto indispensable, máxime en el medio rural y no digamos cuando es uniparroquial, como suele ser frecuentemente; y como Iglesia parroquial y esta, a su vez, como "institución de instituciones" e institución en sí misma, como veremos-y en la novedad y utilidad de considerarlas conjuntamente, es el primero de los dos objetivos que pretende esta aportación. El segundo, mostrar que, efectivamente, es inusual en la historiografía especializada el análisis de esa doble visión y que, por ende, necesita más exploración y que a ello contribuye y ahí reside la relevancia de este texto. Texto que se nutre heurística, metodológica y estructuralmente en la producción científica ad hoc; el examen concienzudo, crítico y comparado de la misma; y la distinción organizada entre lo que sabemos y lo que se aporta nuevo.

\section{ABRIENDO NUEVAS VÍAS: UNA HERRAMIENTA CONCEPTUAL INTERESANTE, INTERDISCIPLINAR Y ÚTIL}

Desde que emergió el Cristianismo, la cruz es el símbolo que cristianiza el territorio. Según la proximidad, ningún territorio, ningún espacio, más cristianizado que el que simboliza y representa la cruz de la Iglesia parroquial, al ser, en jurisdicción, la primera, como indican bien los entierros y otros actos religiosos colectivos del Antiguo Régimen, y desde luego imprescindible en el medio rural. Como acaba de indicarse, este primer apartado delimita el contexto, los términos, las nociones, lo que parece inexcusable para luego atender y entender las contribuciones historiográficas. No obstante, y para que también se capte el interés de la novedad que se planteará, veamos antes lo que sabemos hasta ahora, lo habitual, en relación a la parroquia e institución parroquial como concepto, y luego la nueva vía de conocimiento que este artículo propone y aporta. 


\subsection{Qué conocemos}

Al respecto, lo mayoritariamente frecuente es contemplar la parroquia como jurisdicción o como templo y, en esta acepción, también casi siempre no de forma compleja constituida por varias instituciones, que es como aquí se hará, sino como ente unívoco, y, en todo caso, atendiendo a su origen, definición y ámbito, y cometidos y servidores ${ }^{1}$. Resumiendo estas cuestiones y como preámbulo de lo que, por su novedad, realmente interesa en este primer epígrafe, podemos afirmar que el nacimiento de la parroquia se vincula a la hecatombe abierta con las invasiones bárbaras que en el siglo IV d. C. asolaron las grandes ciudades romanas provocando la huida masiva de sus habitantes hacia las zonas rurales como lugar de asentamiento y mayor seguridad. Esta situación conllevó, de una parte, el surgimiento de numerosas comunidades cristianas, pero, de otra - y al mismo tiempo—, la dificultad del Ordinario para su control, y, por ende, la necesidad de crear la figura del párroco para atenderlas. De esta forma dichas comunidades de fieles acabaron por agruparse de manera permanente en una iglesia particular, a cuyo frente se halla el párroco, responsable de la cura pastoral de la feligresía y de regir los destinos de aquella; de hecho, se configuraba así lo que el derecho canónico, en su canon 515, define como "una determinada comunidad de fieles constituida de manera estable en la Iglesia particular, cuya cura pastoral bajo la autoridad del obispo, se encomienda a un párroco como su pastor propio" (Teruel Gregorio de Tejada, 1993: 297-311; Domínguez Ortiz, 1992: 60-67; Morgado García, 2008: 145-161; Barrio Gozalo, 2010a: 139-198; Catalán Martínez, 2015: 20-25; Gómez Navarro, 2013: 356)².

Con verdadera carta de naturaleza ya en la plena Edad Media, la parroquia es, en efecto, el templo en el que se administran los sacramentos, concurren los fieles para participar en el oficio divino y ser adoctrinados, y está regido por un cura párroco. Entidad, pues, fundamental y vital desde el comienzo de la historia de la Iglesia, sobre todo en el medio rural, y cuyo vocablo tiene diferentes acepciones, conociéndose que aun antes de que se impusiera definitivamente el término diócesis no fue raro que para designarla se utilizara el de paroecia, asimismo puede entenderse por aquella la circunscripción o territorio dependiente en lo espiritual de dicho templo y que sirve para organizar a la ciudad o villa desde el punto de vista administrativo. Precisamente el término colación sería sinónimo de esta última acepción. Y también se define como parroquia o feligresía al conjunto de fieles que dependen, en lo espiritual, del mismo templo, y cuyo cuidado se confía a un presbítero con título de párroco o de administrador parroquial, que puede ser ayudado por uno o más vicarios parroquiales, llamados también tenientes de cura, primero, y, después, coadjutores. De ahí que las parroquias fueron llamadas por antonomasia curatos y los que las regían rectores o curas, y siendo en ellas donde se administraba oficialmente el primer sacramento, o sea el bautismo, recibieron igualmente la denominación de pilas. Institución primaria encargada de la recaudación del diezmo durante todo el Antiguo Régimen, la parroquia también fue históricamente la unidad territorial elemental de la administración tanto civil como eclesiástica, por lo que, en el primer nivel, actuó como centro de empadronamiento, de la fiscalidad

1 Básico para ello, y soporte de los párrafos que siguen, son los trabajos específicos sobre la institución parroquial de Aubrun (2008), Catalán Martínez (2013), Curiel Yarza (2009), Fariña Jamardo (1975), Greco (1984, 2013). López Alsina (2002), Puigvert i Solà (2013), Saavedra-Sobrado-Presedo (2013), o Ventura Gracia (2016b), entre otros, y que serán citados cuando correspondan y desde luego en la relación bibliografía final; a ellos se suman las referencias más genéricas sobre aquélla o para aspectos puntuales de la misma, de también entre otros: Carpio Dueñas (2000), Díaz Ibáñez (1998), García de Cortázar (1974), García de Valdeavellano (1977), Genicot (1993), Peña Bocos (1995), Regatillo (1965), Sánchez Herrero (1978), o Sanz Sancho $(1989,1995)$.

2 Cita textual: Libro II, parte segunda. Capítulo VI. De las parroquias, de los párrocos y los vicarios parroquiales (apud.: Ventura Gracia, 2016b: 61). 
y del reclutamiento de tropas; y, en el segundo, como centro del registro y control de la administración sacramental —desde luego de los tres principales sacramentos de bautismos, matrimonios y defunciones, y del cumplimiento pascual-, desempeñando, por tanto, esas dos fundamentales funciones (Ventura Gracia, 2016b: 61-70; Puigvert i Solà, 2001: 22-24).

De marca netamente rural hasta adquirir los perfiles institucionales que le permitan trascender su nivel inicial, la institución parroquial se convierte así, pues, y desde sus orígenes, en centro y motor dinamizador de las actividades de culto y sacramentales, y, en general, en el espacio donde los feligreses participarán de las principales actividades litúrgicas. Entre el principio y el fin de la vida cristiana, como decíamos, la parroquia reclamará su presencia a la hora de cumplir con el precepto de la misa dominical o fiestas de guardar, recibir los sacramentos, aprender la doctrina cristiana, contraer matrimonio y, en fin, en cuantas ocasiones la Iglesia considere precisas como lugar de reunión, hasta la hora final de sus fieles y el momento de su entierro. Por su parte, estos la visitarán periódicamente para contribuir a su sostenimiento mediante el pago del diezmo y las primicias, sin perjuicio de realizar ofrendas en forma de "limosnas", y ceder en sus testamentos parte de sus bienes, pues, además de lugar de culto y ámbito donde los fieles recibían los sacramentos, la parroquia se constituye también en circunscripción territorial de la administración eclesiástica y elemento esencial de la sociedad preindustrial; y sin duda en el punto de mayor relación entre Iglesia y comunidad cristiana. Por eso, más allá de las funciones religiosas que le son propias, la parroquia se erige en lugar de encuentro, constituyendo su emplazamiento un polo de atracción que determina a veces la creación de núcleos poblacionales o bien su incremento. En realidad, este tipo de parroquia, denominada parroquia medieval o parroquia clásica y que surge tras el proceso de reorganización eclesiástica de la Europa cristiana durante los siglos plenomedievales, reproduce a pequeña escala la organización de la diócesis — de hecho, es su nombre primitivo, como ya sabemos—, con un jefe —el párroco o rector—, rodeado de sus auxiliares — los beneficiados_, un territorio señalado, y un pueblo o grey al que destinar su labor pastoral: He aquí así el cauce local de la práctica religiosa cristiana por excelencia (Curiel Yarza, 2009: 31).

La parroquia viene a significar, por tanto, la célula básica para la organización del territorio diocesano y en torno a la que se articula la mayor parte del clero que la asiste y las diferentes comunidades y asociaciones de laicos, por lo que evidentemente no debe confundirse con otras iglesias de carácter no parroquial (Díaz Ibáñez, 1998: 37 y ss.). Y el templo parroquial, para los feligreses, su lugar de encuentro con la divinidad, al estar consagrado a Dios y a su culto, y por ende ajeno al ámbito profano. De ahí, la veneración y devoción con que aquellos deben permanecer en su interior, como detallan específicamente las Constituciones sinodales cordobesas del obispo Alarcón³. A la par, la Iglesia parroquial es un símbolo y un distintivo para sus feligreses, quienes coadyuvan por medio de mandas piadosas a su arreglo y magnificencia. Por eso, unidos al templo y a su conservación aparecen los conceptos de "Obra y Fábrica", o "Fábrica" y "Obra", términos que aun cuando suelen usarse como sinónimos al referirse a la institución parroquial, sin embargo han de deslindarse a la luz de la documentación. En todo caso, la condición imprescindible para que una iglesia adquiera la condición de parroquia pasa, como ya se ha indicado, por haber obtenido del Ordinario de la diócesis la delegación que autorice la vida sacramental y cultual, y la exigencia de los deberes de la feligresía respecto al mantenimiento de la Iglesia; de ahí que a veces con el paso del tiempo tal iglesia puede adquirir categoría parroquial, como sabemos que sucede, por ejemplo, en el caso de la localidad cordobesa de Montilla con la "ayuda de parroquia" de san Francisco Solano, convertida en parroquia ya en la contemporaneidad. Y

3 Lib. III, Tít. I, Caps. II-IV, fols. 211-215. 
tampoco se pueden considerar parroquias las iglesias conventuales, al estar estas exentas de la jurisdicción episcopal, salvo que explícita y expresamente así lo reciban, como sucederá, precisamente, en el caso de la también localidad cordobesa de Doña Mencía para su convento de dominicos (López, 2008: 163, 175-176. Madoz, 1987: 157-158). Sin olvidar que siempre lo distintivo de la creación de una parroquia, su objetivo primordial, consiste y radica en la cura pastoral o cura animarum que el máximo responsable de la diócesis, o sea, el Obispo, encomienda a los clérigos adscritos a la misma, siendo misión de estos atender a los cristianos con la predicación y la administración de los sacramentos.

En definitiva, la división territorial eclesiástica verdaderamente representativa en la diócesis la constituye la parroquia, hasta el punto de que los intentos señorializadores que cristalizaron durante los siglos bajomedievales, como sucede en tantas poblaciones del Obispado cordobés, lograron establecerse como parroquias - 0 al menos lo intentarony situación debida no tanto a los beneficios económicos que eventualmente pudiera reportar al señor patrón de la iglesia del lugar, cuanto a la independencia efectiva que proporcionaba con respecto a otros núcleos poblacionales. Su poder aglutinador de los moradores del territorio y, en fin, el servicio religioso, quedaba asimismo asegurado. La parroquia, pues, y obviamente el clero que la sirve, pasan a formar parte inseparable de una unidad de convivencia cívico-religiosa determinada, participando de la propia identidad de quienes la componen. No debe entenderse con ello que la vida parroquial quedaba limitada al cumplimiento más o menos fervoroso de una legislación canónica, que, por un lado, configura históricamente a la institución parroquial y, por otro, enumera las obligaciones de clérigos y fieles. Era mucho más, pues, como se ha señalado, "el marco parroquial facilitaba una vivencia comunitaria de la fe, imprescindible para el nacimiento y desarrollo de la vida cristiana, que es esencialmente eclesial (...) previa a cualquier configuración jurídica. En consecuencia, la parroquia debe entenderse fundamentalmente como cauce de la solidaridad cristiana, que se llama caridad"; y como fenómeno de la fe comunitaria inherente a la vida parroquial que constituye el fundamento y principio de la acción integradora que ejercita en cualquier sociedad en la que la Iglesia se inserta y de la que participa (Sanz Sancho, 1995: 50). Podrían ampliarse cada uno de los tres indicados principales perfiles de la parroquia, pues, efectivamente, exegetas e investigadores han profundizado en su origen, ámbito y cometidos, pero por razones obvias de espacio lo indicado puede bastar para trazar una idea global de la misma, y, sobre todo, para llegar a lo que en este texto más importa, que es justamente lo que sigue.

\subsection{Qué se propone, o la nueva vía de conocimiento}

Como acabamos de ver, la Iglesia parroquial fue una institución absolutamente inexcusable en la España del Antiguo Régimen al organizar, controlar y dirigir desde el principio y en primera instancia y plano toda la vida cristiana católica en torno a sí, de tal forma que feligresía se vinculaba a parroquia y viceversa sin entenderse una realidad sin la otra $-\mathrm{y}$ un rasgo casi totalmente perdido en nuestro tiempo al frecuentarse fuera de aquella la práctica sacramental que la identificaba (bautismos, matrimonios, entierros) —, y aun mucho más en el medio rural por esa su prenotada característica de casi exclusiva uniparroquialidad. También es obvio que son aún muy necesarios estudios sobre la Iglesia parroquial rural y su clero, como acaba de explicitarse; y que aquella se muestra como excelente ejemplo de lo que a nivel institucional puede ofrecer el análisis de fuentes como el catastro de Ensenada por incorporar personas físicas y jurídicas y, por ende, complejidad, diversidad y diferencialidad. Pero también, y como ya se indicó, que hasta casi el presente la parroquia se ha visto o solo como jurisdicción, o solo como templo parroquial y, en este caso, además sin percatarse de la cantidad y diversidad de instituciones que puede cobijar 
en su interior; situación que, sin embargo, en modo alguno impide que en sí mismo, como templo, también sea institución plena. Y este el punto gordiano y la genuina aportación de este texto.

En lo que sabemos hasta ahora sobre la parroquia y, específicamente sobre la Iglesia parroquial, hay algo, efectivamente, aún inexplorado en la historiografía ad hoc, como decíamos, y que es la relevancia de esta propuesta, a saber: 1) la Iglesia parroquial distinguida, pues, de parroquia como territorio o jurisdicción y, por tanto, asimilándola a templo-, y específicamente la Iglesia parroquial rural, es "institución de instituciones", al incluir en sí misma otras muy diferentes instituciones como la fábrica parroquial, el asociacionismo religioso indispensable en la Iglesia parroquial desde Trento —esto es, cofradías del Santísimo Sacramento y de ánimas-, obras pías, y por supuesto las omnipresentes capellanías; 2) la Iglesia parroquial es un todo en sí mismo, única forma de fijar bien su contribución al patrimonio eclesiástico global, y de apreciar sus propias diferencias internas; 3) la Iglesia parroquial es institución social y de poder, al ser también ella, en sí misma, como tal recinto sagrado, institución, y tener, por tanto, todos los elementos que identifican a una institución, como veremos; conceptual o teóricamente es aquí donde radica el rasgo definitorio de este texto, por la novedad y muy escasa aplicación — por no decir nula - en los estudios especializados de un esquema metodológico que combina Historia Social e Historia de las Instituciones, y muestra el rendimiento de los préstamos disciplinares —en concreto para la Historia Institucional, el ámbito de la Historia Política y de lo político- al análisis histórico.

En relación a la Historia Social ello significa que el análisis de la Iglesia parroquial, como parte de la sociedad que es, debe tener en cuenta tres ingredientes indispensables como son enfoque, estructura y dinámica sociales (Bernardo Ares, 1995: 74-78): enfoque, como elemento ordenante de la caracterización y organización social estamental del Antiguo Régimen; estructura, por la morfología social diversa y aun heterogénea en su composición y manifestación; y dinámica, en cuanto a cambio y, sobre todo conflicto. En cuanto a la Historia Institucional, poder aplicar los cinco componentes que se asocian al poder, esto es (Albertoni, 1988: 43 y ss.): territorio y organización administrativa —o institución propiamente dicha-; agentes sociales notorios y aun significativos; bases económicas sólidas e importantes sobre todo por la propiedad, la exención fiscal y especialmente la percepción del importante ingreso del diezmo; y multifuncionalidad, pues así es en el caso de la poderosa Iglesia española del Antiguo Régimen, al desempeñar, desarrollar y prestar varias funciones y servicios: Cultuales —litúrgicos, religiosos, espirituales, pastorales-; asistenciales, caritativos o benéficos; cultuales o educativos; sociales — de control pero también de cohesión en la comunidad—; y políticos — servicio al Estado, nacional o local—, y todo ello obviamente manifestándose de forma cohesionada, unificada y unitaria, que solo fraccionan razones pedagógicas, como se muestra: 


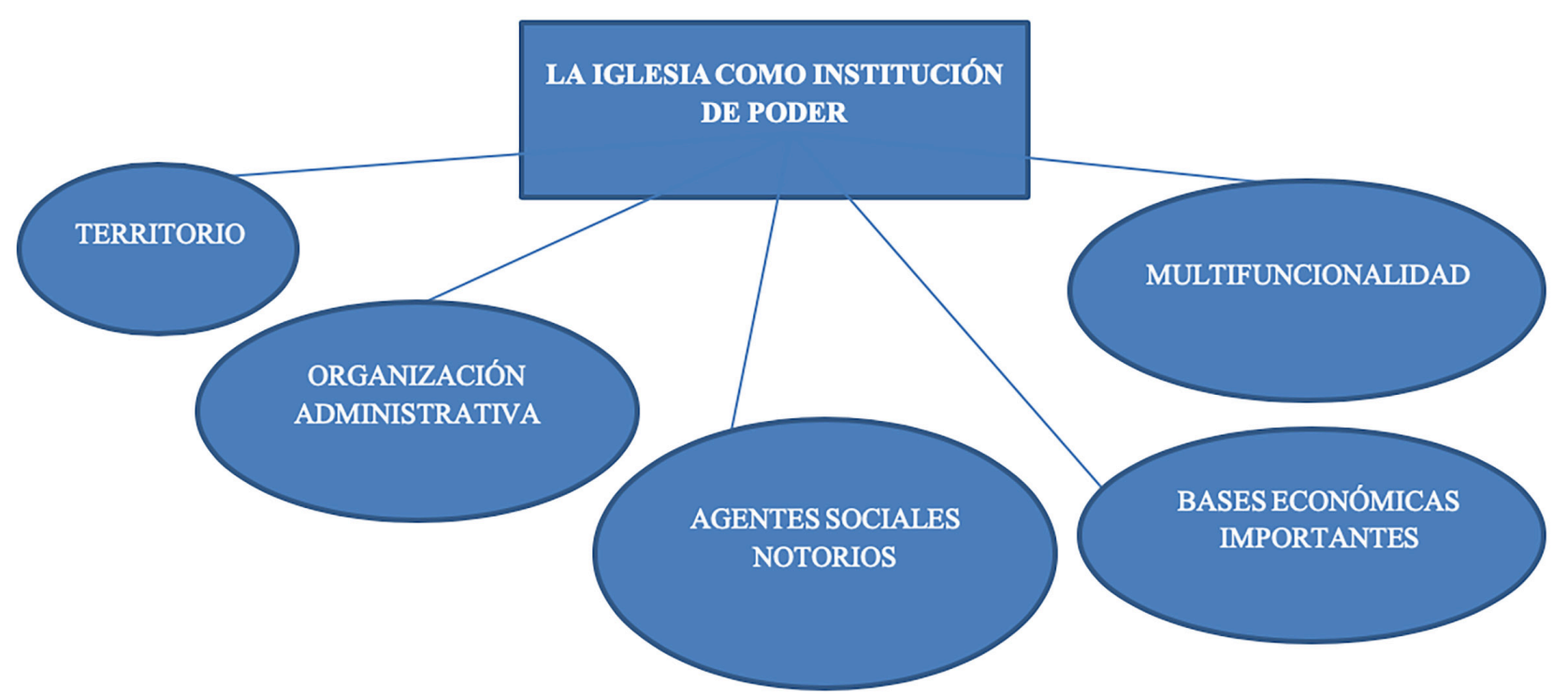

Fuente: elaboración propia

Disponemos así de una herramienta conceptual, interesante, interdisciplinar y útil, como recoge el subtítulo de este apartado -y que puede aplicarse a la Iglesia parroquial porque también es una institución en sí misma, como se ha indicado-: Interesante, porque es inclusiva y versátil, al aunar Historia Social e Historia Institucional y poder aplicarse a todo tipo de estructuras, sistemas o artefactos históricos y culturales que sean instituciones. Interdisciplinar, por incorporar aquellas dos disciplinas. Útil, finalmente, porque permite conocer la composición y funcionamiento de las instituciones como un todo único e integrado, revelando una teoría de la Historia — de la Iglesia, en este caso- que va de la infraestructura a la superestructura y pone el énfasis en lo social —esto es, en el quién es quién y por qué-, y que también se adecúa perfectamente a elementos imprescindibles para el estudio de la Iglesia de la España Moderna, porque territorio y organización administrativa indican cristianización; agentes sociales —personas jurídicas y físicas eclesiásticas-, clericalización; bases económicas sólidas e importantes, espiritualización y patrimonialización, según analicemos instituciones e individuos; multifuncionalidad, por último, sacralización/sacramentalización, si se piensa, en cuanto a este último carácter, en alguno de los servicios religiosos que la Iglesia parroquial presta, y además, teniendo en cuenta lo social, esto es, la diferencialidad, porque qué duda cabe que nos hallamos ante un mundo complejo por diverso y aun heterogéneo.

Sin olvidar otro rendimiento no menos importante y significativo: todo ello puede demostrarse especial y específicamente en la Iglesia parroquial rural tomada, según todo lo indicado, como "institución de instituciones", al reunir varias y diferentes entre sí en su seno y recinto; como un todo, para determinar su contribución al patrimonio eclesiástico global de la localidad pero también su aportación concreta intra, es decir, de las distintas personas jurídicas y físicas que la constituyen, colaborando así a clarificar visiones que no han tenido en cuenta tal distinción, o que han indagado el patrimonio económico eclesiástico desde la tipología de los distintos ramos que lo integran y constituyen -inmueble o raíz urbano y rústico, semoviente, y mobiliario o bienes de capital-, y no desde quienes lo tienen o manejan, es decir, desde las personas jurídicas y físicas; y, sobre todo, como concreción rural de una institución social y de poder como fue la Iglesia española del Antiguo Régimen, que dinamiza, ordena y controla la vida colectiva local en lo religioso y en lo social, y en que ensayar y probar el esquema de análisis indicado. 


\section{EL SOPORTE DE LAS NUEVAS VÍAS: LA HISTORIOGRAFÍA}

Examinados los conceptos, debe abordarse ahora el análisis de la producción científica al respecto que justifica, efectivamente, la novedad de la propuesta que se presenta. Para ello, también dos subapartados se contemplan, uno evidenciando el hasta ahora generalizado déficit de estudios sobre la Institución parroquial; y otro, examinando los que específicamente le corresponden y atañen.

\subsection{La institución parroquial: aún hermana pobre}

Como acaba de indicarse, aún necesita muchas aportaciones la Iglesia parroquial, específicamente la rural, y, en su caso, el bajo clero secular del mismo ámbito espacial, porque, que nos conste, efectivamente, el territorio más privilegiado hasta casi el presente ha sido el alto clero, episcopal y especialmente capitular, donde las aportaciones han sido más abundantes, sobre todo en los últimos años, y señeros los conocidos trabajos ad hoc de Cabeza Rodríguez, Cánovas Botía, Casado Alonso, Díaz Rodríguez, García-Cuevas Ventura, Latorre Ciría, Marín López, Vázquez Lesmes, entre otros; a los que se agregan, por similar temática, los de Aranda Doncel, Barrio Gozalo, Campese Gallego, Cortés Peña, Gil Sanjúan y Pérez de Colosía, López-Guadalupe Muñoz, López Muñoz, o Rodríguez Moli$\mathrm{na}^{4}$. Y, por supuesto, el clero regular, cuya historiografía sin duda es la que más ha crecido, sobre todo en los últimos tiempos, lo que volvería prácticamente interminable la relación de sus aportaciones ${ }^{5}$. Y ello, pese a que hace ya bastante tiempo el profesor Domínguez Ortiz llamaba la atención sobre la necesidad de la historiografía modernista española de saber más acerca del bajo clero secular, en general, y del rural y de las relaciones de los párrocos con sus feligreses, en particular; y también sobre las parroquias, sobre todo de las rurales, y no por falta de bibliografía sobre el estamento eclesiástico, sino por carecer aquel segmento clerical de apologistas propios, como sí tuvo el regular, y, sobre todo, por las pocas aportaciones realmente útiles especialmente al efecto (Domínguez Ortiz, 1992: $6,59)^{6}$. Con muy ligeros matices y variaciones se mantenía prácticamente el mismo aserto y balance algunos años después - aun para épocas posteriores al final del Antiguo Régimen (Cuenca Toribio, 1999: 355-383)—, como revelan por orden cronológico de aparición desde los años noventa del pasado siglo hasta prácticamente el presente, los compendios y reflexiones historiográficas ad hoc de Barrio Gozalo (1990: 793 y ss.), Cortés Peña (1995: 33-35) ${ }^{7}$, Pérez Baltasar (2000: 375-401), Bunes Ibarra (2001: 191-208), Morgado García -especialmente, marcando bien las carencias sobre todo en relación al bajo clero secular y la parroquia, entre las que, curiosa y significativamente, olvida el medio rural (2007a: 5867; 2007b: 84-87)—, Rey Castelao (2007: 198-201), García Hernán (2007: 298-305), Martín Riego y Ruiz Sánchez (2008: 48-54), Cortés Peña y López-Guadalupe Muñoz (2010: 1623), o Soria Mesa y Díaz Rodríguez (2012).

4 Para no alargar innecesariamente el número de las citas, como estas aportaciones no afectan específicamente al contenido de este trabajo, solo se citan en sus autores, porque es sabido que sus trabajos, efectivamente, examinan el alto clero episcopal, arzobispal por lo general secular- o capitular. Por lo demás, y en relación específicamente a los cabildos catedralicios, un buen estado de la cuestión en: Díaz Rodríguez, 2010: 82-99.

5 Por ser de las más recientes, completas, sugestivas y sugerentes, y compendio del estado de la cuestión: Atienza López, 2008: 590. Martínez Ruiz, 2004: 666.

6 Sobre la producción historiográfica del añorado maestro de modernistas relativa al estamento eclesiástico en la España moderna, haciendo especial hincapié en su gran aportación al respecto: Morgado García, 2003: 29-51.

7 Incorpora bibliografía de conjunto y sobre todo específica muy útil sobre distintas expresiones y facetas de la Iglesia andaluza del Antiguo Régimen (pp. 56-133).

8 La aportación del profesor Díaz Rodríguez, "Iglesia y movilidad social en la Monarquía Hispánica: nuevas 
Ciertamente en los últimos años se ha avanzado en el conocimiento de la Iglesia parroquial y de subajo clero secular -intereses que analizaremos casi siempre conjuntamente por su frecuente asociación y vinculación y, por ende, casi imposible segregación-, pero ya podemos adelantar que aún existen lagunas importantes, especialmente en lo relativo a la investigación de aquella institución y colectivo en el medio rural, y que, en todo caso, el balance parece desigual, aun en fechas ya muy cercanas al presente, como ha revelado la documentación manejada para la elaboración de este apartado, donde, que nos conste, solo cuatro revistas especializadas de Historia Moderna han dedicado en algún momento cierta atención monográfica a la Iglesia en la España Moderna —Iglesia y religiosidad; confesionalidad y disciplinamiento social en la Europa católica; Iglesia en la Monarquía Hispánica; y red parroquial en la Europa católica meridional- a saber: Revista de historia moderna: Anales de la Universidad de Alicante, 21 (2003), Manuscrits, 25 (2007), Tiempos Modernos: Revista Electrónica de Historia Moderna, 20 (2010), y Obradorio de historia moderna, 22 (2013). Se observará que no están en el objeto que interesa de la Iglesia parroquial rural y su clero las revistas específicamente centradas en temática eclesiástica como Hispania Sacra o Anuario de la Historia de la Iglesia, pero es porque su vocación genuina es la Historia Eclesiástica, por lo que solo han dedicado artículos sueltos a la iglesia parroquial y al clero secular parroquial, como se verá.

De las cuatro revistas indicadas, la primera no contiene ningún trabajo sobre bajo clero secular parroquial rural ni sobre la parroquia rural; la segunda, solo el ya citado trabajo de Morgado García sobre el estado de la cuestión y últimas tendencias en los estudios acerca del clero en la España de los siglos XVI y XVII; la tercera, únicamente dos aportaciones, una de, nuevamente, Morgado García sobre "Iglesia y familia", y otra, la ya citada conjunta de Cortés Peña y López-Guadalupe Muñoz sobre historiografía de la Iglesia en la Andalucía moderna; y solo la cuarta dedica prácticamente todo el número monográfico señalado a la parroquia, con la excepción de sus dos últimos artículos, aunque solo uno, el firmado por Saavedra, Sobrado y Presedo, específicamente centrado en la red parroquial y clero rural en la Galicia de los siglos XVI a XIX, si bien como investigación en curso. A esas cuatro debe añadirse una quinta, también especializada, como es Studia historica. Historia Moderna, porque en 2007 dedicó un monográfico a "La Historia rural, ayer y hoy" donde no aparece ningún estudio sobre Iglesia parroquial rural, salvo un trabajo en la sección de "Varia" concerniente al papel y la funcionalidad del párroco y el inquisidor ante saludadores y sanadores como instrumentos de construcción cultural identitaria. Y este mismo panorama de muy escasa atención a aquella y a su bajo clero secular se reproduce igualmente si repasamos instituciones culturales de índole provincial como, por ejemplo, la bicentenaria Real Academia de Córdoba, nada receptiva a la hora de abordar el tema que nos atañe. Un análisis riguroso de las actas —unos 163 volúmenes_ que recogen los trabajos expuestos en las sesiones ordinarias durante las tres últimas décadas, así como las de las jornadas celebradas por esta docta institución en distintas localidades cordobesas, recogen tan solo aspectos concretos relacionados con la institución parroquial o bien otras instituciones eclesiásticas afines, sin que el número de trabajos rebasen la decena (Ventura Gracia, 2016b: 48-49). No obstante, tenemos mimbres.

En efecto, sobre una base analizada de bastante significativo número de monografías, revistas y artículos de revistas especializadas de Historia de la Iglesia, y de revistas bien acreditadas y reconocidas de Historia Moderna —Anuario de Historia de la Iglesia, Chronica

respuestas y nuevos interrogantes", pp. 1-5, sintetiza toda la monografía, en realidad, un diferente e interesante estado de la investigación sobre Historia de la Iglesia en la España Moderna al abordarse sus distintas facetas desde la Historia Social. 
Nova, Cuadernos de Historia Moderna, Estudis, Hispania, Hispania Sacra, Historia Social, Investigaciones Históricas, Manuscrits, Mélanges de la Casa de Velázquez, Obradoiro de Historia Moderna, Pedralbes, Revista de Historia Moderna: Anales de la Universidad de Alicante, Studia historica. Historia Moderna, Tiempos modernos, Trocadero: revista de historia moderna y contemporánea, Vínculos de Historia-, así como aportaciones especializadas en publicaciones conjuntas - libros en colaboración y resultados de distintas reuniones científicas- de casi las tres últimas décadas o incluso más, por cuanto cuando la revista o el soporte seriado en cuestión de que se tratara ha sido suficientemente importante o conocido, lo hemos vaciado desde su inicio, y todas localizadas tras una búsqueda bibliográfica selectiva aunque bastante detenida, detallada y detallista, no obviamente cerrada o total porque sería imposible, y aun absurdo teniendo en cuenta la actual bulimia publicadora en concreto sobre Historia de la Iglesia en la España Moderna, pero sí exhaustiva y de interés, exponemos los resultados alcanzados, centrándonos solo y exclusivamente en lo que interesa a este texto - esto es, Iglesia parroquial rural y bajo clero secular de la misma institución y medio-, distribuidos y analizados según su orientación y vocación espacial, en historiografía internacional, nacional y local —en el sentido de Córdoba ciudad y obispado-; para concluir con unas consideraciones globales al respecto, sobre las que ya podemos adelantar, al menos en cuanto al número - y naturalmente entre las aportaciones fichadas y analizadas-, que la primacía la lleva la historiografía citada en segundo lugar y que, en todo caso, se hallan pocas monografías y bastante desmigajamiento en temáticas y asuntos tratados.

\subsection{Los estudios sobre la institución parroquial}

Teniendo en cuenta, pues, todo lo indicado, veamos el panorama que se dibuja en autorías, líneas y principales aportaciones.

A nivel internacional, la más frecuentada ha sido sin duda la Europa del sur —lo que es hasta cierto punto lógico aunque tampoco es descartable la influencia en este aserto de la circunstancia idiomática y/o de la mayor facilidad de contactos investigadores entre los distintos colegas expertos en la materia-, como sucede en Francia con las aportaciones, por lo general tras las huellas de Le Bras (1955), de Ferté (1976), Loupès (1993), Goujard (1996), Bonzon (1999), Restif (2006), Aubrun (2008), Brumont (2013), o Léonard (2016); en Italia, con los trabajos de Greco (1984, 2013); e incluso en Hispanomérica, casos de Argentina y Méjico, con Ayrolo (2008), y Gato Castaño e Icaza Longoria (1987, 2011, respectivamente). En todo caso $-\mathrm{y}$ obviamente siempre sobre los estudios controlados y refiriéndonos a la parroquia y su clero y, a ser posible, en el medio rural-, por lo general alusiones o referencias puntuales a la primera o para un ámbito muy amplio como es la diócesis de París - caso del estudio de Ferté-, análisis de varios y distintos aspectos de la vida religiosa, y etapas previas a la época Moderna o antes del Setecientos, centuria que es la que más nos interesa.

A nivel nacional, y obviamente junto a los consabidos repertorios de consulta y obras globales sobre Historia de la Iglesia en la España Moderna, donde destacan las dirigidos por Aldea-Marín-Vives, y Llorca y García-Villoslada, respectivamente; y específicas, sobre el estamento eclesiástico, y en concreto el clero, donde inexcusables son las aportaciones al respecto del ya varias veces citado Domínguez Ortiz (1992) y Barrio Gozalo (2010a, 2010b), entre otros, dos grandes conjuntos se dibujan, a saber: por un lado, monografías; por otro, aportaciones más breves y sueltas.

Entre las primeras - de norte a sur y de este a oeste de España-, por supuesto indispensables son las monografías de Fariña Jamardo (1975), estudio muy serio sobre la influencia de la aquella en su medio, sobre todo en el gallego que se analiza, y de las pocas 
que se centran específicamente en el medio rural; Catalán Martínez, para conocer el mundo económico del clero vasco a partir de sus funciones cultuales (2000); Curiel Yarza, para la organización eclesiástica parroquial bajomedieval (2009); Porres Marijuán, compilando una excelente obra conjunta de especialistas en los distintos aspectos que trata de la Iglesia vascongada (2015), o Benito Aguado para la vitoriana (2001); Linage Conde, para la vida religiosa parroquial a través de una magnífica y aun poco explotada fuente a tal fin como son las visitas diocesanas (2017); Higueruela del Pino, para el clero manchego e incluso la diócesis primada, aunque prácticamente para la época contemporánea, al dedicar solo a la precedente las décadas finiseculares del Setecientos $(1979,2003)$. Como sucede, pero ahora por lo contrario, por alejarse al extremo cronológico más opuesto, la época medieval, con el trabajo de gran interés y reciente aparición de Ayllón Gutiérrez (2015), o para épocas posteriores, y para Cádiz ciudad y obispado, con las aportaciones de Antón Solé (1994), Morgado García (1989, 1996, 2000, 2008, abundante y extraordinaria producción que casi genera ya historiografía propia y específica sobre el clero andaluz, en general, y gaditano, en particular), y Benítez Barea (2001, 2013, y autora especialmente significativa por ser de las pocas monográficamente centradas en el bajo clero rural del Setecientos y, por ende, bastante cercana a los intereses investigadores de quien este artículo suscribe). Y González Polvillo (1994), Ruiz Pérez (2007), Martín Riego (1999), o Candau Chacón para dos localidades sevillanas — los dos primeros autores citados-, la archidiócesis hispalense —el tercero-, y una importante vicaría sevillana —la cuarta historiadora-, respectivamente, y todos ellos con visiones de conjunto sumamente útiles; tratando más facetas que la sola eclesiástica rural; una de las cuestiones más técnicas y complejas cual es la de la naturaleza, requisitos y proceso de promoción y ascenso del clero parroquial, y su evolución en la larga duración; o la vida eclesiástica parroquial de la Baja Andalucía en su conjunto —-sociología de sus miembros, formación, obligaciones, recursos económicos y gestión, pero también problemática y desvíos-, como realiza la profesora Candau, seguramente una de las investigadoras más idóneas para aquel campo y también de las que mejor lo conocen, con su excelente producción historiográfica al respecto (1986, 1993a, 1993b, 1994), hasta el punto de que aquella es, efectivamente, una de las áreas andaluzas -y aun españolas - mejor y más estudiadas en esta temática.

Por su parte —y obviamente aún dentro de la historiografía nacional—, las aportaciones sueltas, emanación de artículos de revistas especializadas, obras en colaboración y resultados de reuniones científicas en forma de actas o de libros ad hoc, sobre bajo clero secular e institución parroquial constituyen el conjunto más numeroso, como era por lo demás esperable porque la actividad investigadora al respecto ha sido bastante fructífera sobre todo en las dos últimas décadas y hasta casi el presente, aunque no tanto como en otros colectivos clericales seculares — cabildos catedralicios y alto clero, como ya dijimos_y por supuesto el clero regular. Ello significa que sobre la ya indicada base documental consultada, temática, espacial y cronológicamente hemos reunido un buen número de aportaciones que han versado, planteado o rozado la parroquia y el clero secular rural, sobre todo en el Setecientos, si bien no siempre de forma específica, pues he analizado trabajos y estudios sobre la institución parroquial; el clero y la Edad Moderna generosamente entendidos, es decir, bajo clero secular; y a veces arrancando desde la etapa pleno-bajomedieval y hasta las primeras décadas del Ochocientos, para que el estado de la cuestión sea lo más completo y rico posible.

Se han obtenido así seis grandes grupos temáticos creados según el asunto, perspectiva o enfoque dominante en el contenido de las distintas contribuciones y única forma posible de manejar una información bastante amplia, variada y a veces aun dispar y, por tanto, desde lo historiográfico o historiográfico-metodológico, hasta lo cultural, pasando 
por lo demográfico, económico, social, y profesional-institucional; a ellos debe añadirse uno más para aquellos trabajos que tratan varios de esos aspectos diferentes a la vez. El balance es interesante por cuanto refleja bastante bien no solo esa prenotada dificultad metodológica de adscribir a uno u otro grupo algunas publicaciones por la concurrencia de varios contenidos distintos y, por tanto, de diseccionar; sino también, y sobre todo, las líneas más transitadas o atrayentes por la historiografía española especializada en los últimos años. Razón por la cual la sección menos nutrida es la relativa a trabajos de contenido demográfico, seguida por los que indagan los aspectos concernientes a la profesión clerical o a la institución parroquial propiamente dicha, y los historiográficos o historiográficosmetodológicos; y destacan, de menos a más, el grupo de aportaciones de índole económica —importante—, social — bastante abundante_ y cultural, la más nutrida. Y por supuesto también consta buen paquete de trabajos en esa "miscelánea" que tocan varias de esas facetas a la vez. Ese es, pues, el itinerario de la exposición que sigue, previa aclaración de que en aras del mayor y mejor conocimiento, obviamente superamos el mero listado de aportaciones en cada grupo analizando o explicitando los matices que aporta cada estudio en su grupo correspondiente.

Así —comenzando por las aportaciones de contenido historiográfico o metodológico-, siete son los trabajos que, entre todos los consultados, insistimos, respaldan esa temática como denominador común de las respectivas propuestas, a saber: Análisis del clero desde la Historia Social (Benito Aguado, 1994); la parroquia rural como objeto de análisis y desde asimismo la Historia Social en distintas manifestaciones de aquélla, así como de algunas de sus instituciones emblemáticas como son las fábricas parroquiales y el asociacionismo religioso, y su sociabilidad con los fieles (Puigvert i Solà, 2013); desde nuevas fuentes como los archivos diocesanos de la Curia que permitirán conocer mejor las fórmulas empleadas en la administración de los bienes patrimoniales y beneficiales del bajo clero (Cabeza Rodríguez, 1991); las anotaciones parroquiales como fuente para estudiar y conocer la demografía de ciclo antiguo (Rueda Fernández, 1990); las visitas como forma y vía de conocer al clero rural (Candau Chacón, 1983); libros parroquiales y otras fuentes censales y notariales para el estudio de la población (Barbazza, 1997); o tomar los libros de cumplimiento pascual y otra documentación sobre el estado de la parroquia como fuentes para el estudio de la población (Sabaté i Bosch, 2009).

Por su parte, abordan lo demográfico las contribuciones que analizan el número y estructura del clero secular español en su conjunto (Blanco Carrasco, 2018), o granadino encargado de la recristianización de la diócesis a comienzos del Quinientos (LópezGuadalupe, 2003-2004); o efectivos, distribución, estructura y evolución del clero secular murciano, así como su participación en el conjunto de la población laica en el Seiscientos (Irigoyen López, 1997a).

Un buen paquete de textos se centran en los asuntos crematísticos o materiales: Rentas económicas y diferencias por las mismas en el seno del clero (Bravo Lozano, Colás Latorre, ambos 1994); reacción del clero ante los procesos de posible discusión y/o supresión de la amortización (Palao Gil, 1994); ramos, distribución y gastos de la economía eclesiástica (Barrio Gozalo, 1994-1995); colaboración y aportación fiscal del clero a las cargas del Estado (Carpintero Aguado, 1996); normativa y regulación legal de uno de los ingresos específicos del clero parroquial como es la congrua (Barrio Gozalo, 1991); realidad contable de la institución parroquial, sobre todo a través de la administración y control de las capellanías y cofradías (Castro Pérez, 2007); situación económica del clero parroquial sevillano según las percepciones de sus oficios eclesiásticos en el tránsito del Cuatrocientos al Quinientos (Pérez González, 2012); análisis del régimen interno y administración económica de los cabildos de clérigos seculares, concluyéndose que aunque 
sus actividades y vida económica no eran relevantes tampoco estaban estancadas (García Arancón, 1999); examen de las anotaciones contables por funeración en los libros ad hoc parroquiales como fuente importante de ingresos en la colecturía parroquial (Castro-CalvoGranado, 2007), o de la renta global y cargas en contra a fin de obtener el líquido disfrutable para el bajo clero segoviano durante el Setecientos (Barrio Gozalo, 1992).

Aumenta el número de colaboraciones -y ya estamos en el conjunto número cuatro de los seis que habíamos establecido según el tenor o línea dominante de los distintos contenidos-, con aquellas que tienen por cordón umbilical la temática social, aunque aquí con muchos perfiles, derivaciones y matices, a saber: clero y familia, en cuanto acogimiento a la casa del clérigo y a su patrocinio como una forma de medro y movilidad social; relación entre los sirvientes de clérigos y el posible emprendimiento y aseguramiento en la profesión eclesiástica de los primeros; o análisis del tipo de hogar del clérigo secular y de sus fuentes de mantenimiento (Irigoyen López, 1997b, 2001, 2007, 2009, 2016). Élite eclesiástica rural (Benítez Barea, 2018). Familias poderosas, poder municipal y fundación de capellanías como ámbitos de poder social (Arroyo Vozmediano, 2008); clérigos seculares, lazos familiares y familia como apoyo y beneficio, recíprocamente, de los primeros (Morgado García, 2010b); clero, empleados de su casa y ordenación del hogar (Morán Corte; Tovar Pulido, ambos 2018); clérigos y familias de notoriedad social (Sanz de la Higuera, 2002); sociabilidad e institución parroquial, diferencias sociales entre el propio clero rural, su implicación parentelar con los agregados y familias más acomodadas (Saavedra-SobradoPresedo, 2013); análisis del clero parroquial desde la doble perspectiva humana y religiosa del colectivo para conocer su nivel de incidencia e implicación en las relaciones sociales y productivas de las comunidades concejiles y rurales en que se inserta (Rubio Pérez, 2013), o de su específica institución, la parroquia, como generadora de sociabilidad y solidaridades (Rubio Pérez, 2018). Estudio de las relaciones sociales y afectivas del bajo clero secular rural con familia, allegados y vecinos, solidaridades y expectativas mutuas que suscita (Benítez Barea, 2000-2001, 2012, respectivamente); clero y familia en los hogares en que aquel es cabeza de casa y familia según el catastro de Ensenada (Sanz de la Higuera, 2007); familia y derechos de presentación en las características iglesias propias del norte de España (Díaz de Durana Ortiz de Urbina, 1998); importancia del factor familiar en la creación y promoción del clero secular, pero también influencia de éste en la posición de la "casa" o el clan familiar (Artola Renedo, 2010); influencia de la familia en la conformación y mejora de la carrera eclesiástica del clérigo rural, en su promoción y renovación (Candau Chacón, 1997); o también aquélla como forma de ascenso, dinámica y cambio social (Morgado García y Olival-Monteiro, ambos 2006).

Por su parte, atienden los aspectos relacionados con la dimensión profesional o profesional-institucional de la condición clerical un número menor de trabajos, como decía, que estudian formación y asociacionismo laboral del clero parroquial (Aranda Pérez, 2000); evolución de los ingresos en órdenes sagradas (Pueyo Colomina, 1994); asociacionismo clerical como forma de influir en la sociedad local y añadir rentas a los beneficios parroquiales (Ayllón Gutiérrez, 2014); análisis del oficio y el beneficio eclesiásticos como la genuina expresión institucional del clero rural castellano en los siglos bajomedievales (Martín Martín, 2005), o de los requisitos y proceso de colación de los curatos en la segunda mitad del Setecientos (Ucero i Ramón, 1988b); y también condiciones necesarias, filtros y procedimiento de acceso a la clerecía secular y sus posibilidades de ascenso y promoción según las Constituciones sinodales, o el impacto del reformismo borbónico en determinados aspectos institucionales como provisión de beneficios y red parroquial (Morgado García, 2009, 1992, respectivamente). 
Yes por supuesto el bloque más abundante, como ya avancé, el que acoge aportaciones cuyo denominador común o hilo conductor es el nivel de la superestructura, la temática cultural o lo cultural en sentido muy amplio, esto es, mentalidades y comportamientos — regulares e irregulares, modélicos o transgresores-, percepciones, problemática y conflictividad, o rol del clero secular entre su sociedad; en definitiva, cultura material e inmaterial. Aquí, pues, trabajos que han analizado visiones del mundo, modos de vida y mentalidad del clero secular y diferencias de éstos entre el alto y bajo clero, y necesidad de mejorar siempre el nivel moral del clero, bien de forma general (Álvarez Santaló, 2000) o de casos concretos, como el cacereño (Testón Núñez y Santillana Pérez, 1983); funcionalidad del clero secular como mediador en los conflictos rurales (Mantecón Movellán, 1994); participación del estamento eclesiástico en la dinámica política problemática de las agitaciones aragonesas de finales del Quinientos, española del Setecientos, del conflicto napoleónico (Gascón Pérez, 1994; González Cruz, 2008; Riera i Fortiana, 1982, respectivamente); el clérigo como posible animador y dinamizador sociocultural (Gil Bautista, 2018); la posición del clero parroquial y diocesano en las cuestiones y contenciosos civiles (Cortés Peña, 2006), y el control del clero sobre las relaciones personales y sociales (Lara Ramos, 2003); formas de pensar y conducta social (Sánchez González, 1994); coherencia de profesión eclesiástica y actuación vital, formación moral y adecuada a la dignidad clerical (Martín Riego, 1995; Irigoyen López, 2008, respectivamente); la posesión y significado de determinados artefactos culturales materiales en el clero como sus atuendos (Sanz de la Higuera, 2013); el conocimiento de la cultura material e inmaterial, los modos de vida y mentalidad, de algún miembro concreto del bajo clero como los rectores a través de los inventarios post mortem, así como del alto y bajo clero a través de la misma escritura notarial pero para el caso sevillano y las diferencias internas que su investigación arroja (Collelldemont Vives, 2008; Álvarez Santaló y GarcíaBaquero González, 1996-1997, respectivamente); o celebraciones y manifestaciones religiosas en los tiempos litúrgicos acostumbrados y fuertes de la parroquia rural (Ucero i Ramón, 1988a).

Y también en este ramillete de aportaciones de contenido o cariz cultural las que han planteado, considerado y/o subrayado la violencia intra y extraestamental del clero diocesano a través del caso burgalés a comienzos de la modernidad, reflejo de sus fuertes tensiones sociales (Díaz Ibáñez, 2015); la necesidad de mejorar el deficiente nivel cultural y formación de los clérigos a fines de la Edad Media (García Pardo, 1999); analizar la parroquia desde la historia del arte (Miranda Díaz, 2016), la contribución cultural de la parroquia indagando los ámbitos, instrumentos y fines de la música (Pomar Rodil, 2017), 0 esta última actividad en la parroquia rural (Pérez Mancilla, 2013); o la precisión de mejorar el nivel cultural del clero secular continuando la fundación de seminarios conciliares (Barrio Gozalo, 2002), y estudiar la cultura del libro según la tenencia o conocimiento de éste por parte del clero barcelonés en el Setecientos (Burgos Rincón, 1996).

Cierran las siete categorías indicadas ese amplio grupo de trabajos que hemos denominado "miscelánea" por afectar o tocar varios aspectos diferentes a la vez en relación al bajo clero secular y rural, clero parroquial, o parroquia, principalmente. Aquí están, pues, los que tratan sobre estructura administrativa diocesana, régimen de patronato, sistema beneficial, niveles de renta del clero parroquial (Catalán Martínez, 2013, 2015); demografía, clero secular como grupo social, formación y acceso, y bases económicas (Bada Elías, 1995). Reclutamiento, formación, situación económica y moral; demografía y economía del clero diocesano; estructura parroquial, acceso a los beneficios, cultura y moralidad; e impacto del reformismo borbónico (Morgado García, 1990, 1991, 1995, 2013). Formas de financiación como los diezmos, sociedad, familia y clero (Rodríguez Cancho y Blanco Carrasco, 2008); demografía, urbanismo, vecindario, parroquia como territorio (Luna 
Díaz, 1980); demografía eclesiástica, extracción social, bases económicas, relaciones sociales, moralidad (Larrea y Mieza, 2011); distinción entre parroquia como jurisdicción, territorio o demarcación, e Iglesia parroquial, estructura parroquial, relación con feligresía y demás instituciones eclesiásticas, y condiciones económicas (Franco Rubio, 1981); estructura diocesana, clero parroquial, situación general de la ciudad y de la religiosidad de los fieles según las visitas ad limina y las pastorales (López-Guadalupe Muñoz, 1992, 1996); efectivos, formación y conducta (Sánchez González, 1994); aspectos económicos, familiares, sociales y culturales del clero sevillano bajomedieval según su documentación notarial (Pérez González, 2009); vocaciones clericales, comportamientos demográficos y conductas (Candau Chacón, 2001); o situación económica, familiar y social, modos de vida y mentalidad del clero de Coria a través del catastro de Ensenada y documentación notarial (Aragón Mateos, 1995). Termina también así este punto dedicado a la historiografía nacional sobre la institución parroquial y su clero secular. Lo abrochan definitivamente las aportaciones realizadas desde y para el ámbito local, entendido, según ya se dijo, como Córdoba ciudad y obispado.

A cuyo respecto muy pocas se han sumado aún en relación a aquella temática en los últimos años, pues si bien a las consabidas de Aranda Doncel (1990), González Torrico (2010), Valenzuela García (2008a, 2008b, 2009), Nieto Cumplido (2003), Flament (2010) o Herrera Mesa (2004), estos tres últimos, sobre la diócesis, bien con una visión general sobre la cordobesa y jiennense, o específica de la primera a través de sus visitas ad limina, o de los textos de sus prelados, han de añadirse estudios sobre la institución parroquial dados a las prensas como obras en colaboración o independientes, el panorama es aún bastante magro. Entre las primeras estarían las investigaciones de Nieto-Márquez Marín (2009), Segado Gómez (2016), y, sobre todo, de Ventura Gracia que con sus trabajos sobre aspectos concretos de la parroquia como la música y las capellanías, o sobre toda la institución parroquial $(2010,2012,2013,2016 a, 2016 b, 2017)$, trasluce de manera incontestable el papel que juega esta en aquellas, pero también, y a su vez, las capellanías en la misma parroquia rural. Entre las monografías, indispensable citar los estudios de Pérez Peinado (2013) y, sobre todo, el ya indicado espléndido, por ser modélica investigación al respecto, de Ventura Gracia (2016b). Sin embargo, y como decía, la conclusión más sólida observando la historiografía local es la imperiosa necesidad de seguir indagando la institución parroquial, más aún rural, y, sobre todo, hacerlo desde la óptica y enfoque que aquí he tratado de presentar.

\section{CONCLUSIONES}

Termina aquí el camino empezado líneas arriba. Y para ello solo las dos observaciones más significativas, según la doble organización de este texto, a saber: lo novedoso y enriquecedor de una visión global para la investigación de la parroquia; la necesidad de seguir profundizando historiográficamente en el conocimiento de la institución parroquial y de su clero, y específicamente para el medio rural.

Por lo que concierne a lo primero, hemos intentado mostrar la relevancia de la propuesta realizada, precisamente por la novedad que representa su enfoque o perspectiva en la historiografía especializada. En efecto, sin orillar la parroquia como jurisdicción, que obviamente está presente porque la ejerce sobre todas las instituciones eclesiásticas de su demarcación —máxime en el medio rural, y más aún si es uniparroquial—, abordamos y entendemos la parroquia como Iglesia parroquial, esto es, como un todo único y conjunto suma de las varias y muy diferentes entre sí personas físicas y jurídicas, individuos e instituciones, que alberga y cobija; y desde la concepción de la Iglesia como institución social y de poder, que la misma parroquial concreta, es decir, con sus cinco componentes 
de territorio y organización administrativa, agentes sociales notorios y aun significativos, bases económicas importantes, y multifuncionalidad, y que respectivamente hemos denominado cristianización, clericalización, espiritualización y patrimonialización de bienes, y sacralización-sacramentalización. Y esa doble visión, siempre abordada desde la multiplicidad de fuentes y la cartografía histórica, otra aportación al conocimiento modernista ad hoc. Se perfila así una imagen mucho más enriquecedora y sobre todo novedosa de la Iglesia parroquial, un todo único y conjunto y, a la par, plural y diverso, hecho de instituciones y personas. El beneficio es la figura central de las primeras; sus clérigos, de las segundas; y todo ello, una organización político-administrativa bien engrasada y dimanada de la normativa sinodal al efecto que explicita perfectamente cargos, cometidos y funciones.

En cuanto a lo historiográfico, sobre la incontestable constatación de que indudablemente se ha avanzado en el conocimiento sobre la parroquia y su clero —si bien no tanto en relación al medio rural-, donde las aportaciones señeras de Domínguez Ortiz o Barrio Gozalo al respecto siguen siendo absolutamente indispensables; de que casi ese mismo nivel alcanzan los trabajos monográficos acumulados hasta el punto de que algunos investigadores como Benítez Barea, Candau Chacón, Irigoyen López o Morgado García, por citar solo el ámbito meridional peninsular, han generado casi una historiografía propia sobre el tema; que tampoco es innegable cierta dispersión a veces en los contenidos indagados, pese a la sistematización lograda en los seis grandes bloques temáticos más concurridos que se han examinado; o la existencia de algunos puntos comunes señalados por toda la historiografía especializada — axialidad de la parroquia, y de forma especial en el medio rural por su prácticamente absoluta uniparroquialidad; complejidad del bajo clero secular por su intrínseca desigualdad, social y económica; importancia de la familia también en tal estrato clerical; o necesidad de seguir mejorando su nivel cultural incluso bien avanzado el Antiguo Régimen, y de prestar más atención a la relación entre clerecía y feligresía tanto en tiempos de paz como de posibles conflictos-, aún una llamativa y clamorosa ausencia. Faltan más estudios sobre la parroquia rural, específicamente, sobre la Iglesia parroquial en el medio rural, e indagada desde la concepción y enfoque que aquí la hemos presentado. Esto es, como compendio global de instituciones e individuos, de personas jurídicas y físicas, y desde la Historia Social e Institucional, doble concepción y enfoque, que nos conste, aún bastante ausente de la producción historiográfica analizada, de la academia en suma. Ciertamente hemos detectado algunas coincidencias en algunos trabajos por haberse apoyado en el catastro de Ensenada, subrayado y explorado el conocimiento de los hogares de los clérigos seculares, o indicado las diferencias dentro de un colectivo eclesiástico menor pero muy importante como es el bajo clero parroquial del Antiguo Régimen —aportaciones de Aragón Mateos, Irigoyen o Sanz de la Higuera-, pero parece que se carece - insistimos, que nos conste- de una concepción de la Iglesia parroquial rural como la aquí se ha expuesto, a nuestro juicio, útil, diferente y novedosa, y vacío que, a través del caso palmeño, empezamos a llenar.

\section{BIBLIOGRAFÍA}

Albertoni, E. A., "Teoría de las élites y elitismo (apuntes para un análisis histórico y actual)", Sistema: Revista de ciencias sociales, 83 (1998), pp. 43-56.

Álvarez Santaló, L. C., "'Vivir como un cura'. Algunas precisiones cuantitativas respecto al imaginario social sobre el clero en el siglo XVIII", en Aranda Pérez, F. J. (coord.), Sociedad y élites eclesiásticas en la España Moderna, Cuenca, Universidad de Castilla-La Mancha, 2000, pp. 101-147.

Álvarez Santaló, L. C. y García-Baquero González, A., "Riqueza y pobreza del clero secular en la Sevilla del Antiguo Régimen (1700-1834)", Trocadero: Revista de historia 
moderna y contemporánea, 8-9 (1996-1997), pp. 11-46.

Antón Solé, P., La iglesia gaditana en el siglo XVIII, Cádiz, Universidad, 1994.

Aragón Mateos, S., "Notas sobre el clero secular en el antiguo régimen: los presbíteros del obispado de Coria en el siglo XVIII", Hispania sacra, 95 (1995), pp. 171-216.

Aranda Doncel, J., "Los bienes eclesiásticos en Iznájar a mediados del siglo XVIII", en Aranda Doncel, J. (coord.), Encuentros de Historia Local. La Subbética, Baena, Adisur, 1990, pp. 317-326.

Aranda Pérez, F. J., "El clero parroquial también se acabilda. El cabildo de curas y beneficiados de Toledo", en Aranda Pérez, F. J. (coord.), Sociedad y élites eclesiásticas en la España moderna", Cuenca, Universidad de Castilla-La Mancha, 2000, pp. 237-287.

Arroyo Vozmediano, J. L., "Iglesia, poder municipal y fundación de capellanías en Calahorra (1600-1710)", Revista de historia moderna: Anales de la Universidad de Alicante, 26 (2008), pp. 189-220.

Artola Renedo, A., "Roles de los eclesiásticos seculares en el gobierno doméstico de las élites vascas (1700-1837). Algunas notas e hipótesis", en Imízcoz Beunza, J. M. y Oliveri Korta, O. (eds.), Economía doméstica y redes sociales en el Antiguo Régimen, Madrid, Sílex, 2010, pp. 419-444.

Atienza López, A., Tiempos de conventos: una historia social de las fundaciones en la España moderna, Madrid, Marcial Pons, 2008.

Aubrun, M., La paroisse en France des origines aux XVIe siècle, París, Picard, 2008.

Ayllón Gutiérrez, C., "Cabildos de clérigos en la Baja Edad Media. Los casos de Alcaraz (Albacete) y Tresjuncos (Cuenca)", Hispania sacra, 66/2 (2014), pp. 7-55.

- Iglesia rural y sociedad en la Edad Media (Alcaraz y Señorío de Villena), Madrid, Sílex, 2015.

Ayrolo, V., "Concursos eclesiásticos como espacios de ejercicio de poder. Estudio de caso: los de la sede cordobesa entre 1799 y 1815", Hispania sacra, 122 (2008), pp. 659-681.

Bada Elías, J., "Iglesia y sociedad en el Antiguo Régimen: El clero secular", en Martínez Ruiz, E. y Suárez Grimón, V. (eds.), Iglesia y Sociedad en el Antiguo Régimen, I, Las Palmas de Gran Canaria, Universidad, 1995, pp. 81-91.

Barbazza, M.-C., "Registros parroquiales, particiones de bienes y censos de población. Historia de las familias campesinas y parentesco en Castilla la Nueva en los siglos XVI y XVII", en Chacón Jiménez, F. y Ferrer i Alòs, LI. (eds.), Familia, casa y trabajo, Murcia, Universidad, 1997, pp. 161-168.

Barrio Gozalo, M., "El bajo clero en la España del siglo VXVIII. Estado de la cuestión, problemas y direcciones de la investigación actual", Coloquio Internacional Carlos III y su siglo, I, Madrid, Universidad Complutense, 1990, pp. 793-805.

— "Las condiciones materiales del clero parroquial del obispado de Segovia en el siglo XVIII. Normativa legal sobre sus ingresos o 'Congrua clerical'”, Investigaciones Históricas: Época moderna y contemporánea, 11 (1991), pp. 9-34.

— "Las condiciones materiales del clero parroquial del obispado de Segovia en el siglo XVIII (II): La realidad de los ingresos y los gastos, Investigaciones Históricas: Época moderna y contemporánea, 12 (1992), pp. 113-138.

— "La proyección económica de la Iglesia en el mundo rural español durante el Antiguo Régimen", Trocadero: Revista de historia moderna y contemporánea, 6-7 (1994-1995), pp. 7-34.

— "El clero bajo sospecha a principios del siglo XVIII: El Informe de Macanaz y la respuesta de los obispos", Investigaciones históricas: Época moderna y contemporánea, 22 (2002), pp. 47-62.

- El clero en la España Moderna, Córdoba, CSIC-Cajasur, 2010a. 
- El sistema beneficial de la Iglesia española en el Antiguo Régimen (1475-1834), Alicante, Universidad, 2010b.

Benítez Barea, A., "El clero de Alcalá de los Gazules y su entorno en el siglo XVIII", Trocadero. Revista de historia moderna y contemporánea, 12-13 (2000-2001), pp. 123-141.

— El bajo clero rural en el Antiguo Régimen (Medina Sidonia, siglo XVIII), Cádiz, Universidad, 2001.

— "Bajo clero y familia en la Comarca gaditana de la Janda durante el Antiguo Régimen", en Pérez Álvarez, Ma J. y Martín García, A. (coords.), Campo y campesinos en la España Moderna; culturas políticas en el mundo hispano, 2, Madrid, FEHM, 2012, pp. 10491061.

- Clero y mundo rural en el siglo XVIII. La comarca de la Janda, Cádiz, Universidad, 2013.

- "La jerarquía eclesiástica rural: Vicarios y beneficiados de Alcalá de los Gazules en el siglo XVIII", en Serrano Martín; E. y Gascón Pérez, J. (eds.), Poder, sociedad, religión y tolerancia en el mundo hispánico, de Fernando el Católico al siglo XVIII, Zaragoza, Institución Fernando el Católico, 2018, pp. 1227-1240.

Benito Aguado, M. T., "Clero e Historia Social; nuevas perspectivas de estudio", en Martínez Ruiz, E. y Suárez Grimón, V. (eds.), Iglesia y Sociedad en el Antiguo Régimen, I, Las Palmas de Gran Canaria, Universidad, 1994, pp. 41-46.

- La sociedad vitoriana en el siglo XVIII: el clero, espectador y protagonista, Bilbao, Universidad del País Vasco, 2001.

Bernardo Ares, J. M. de, Historiology, research and didactis: Elaboration and Transmission of Historical Knowledge [Elaboración y transmisión de los saberes históricos- Historiología, Investigación y Didáctica], Bethesda, International Scholars Publications, 1995.

Blanco Carrasco, J. P., "En la casa del cura. El clero y sus familiares en la Edad Moderna (Interior peninsular, siglo XVIII)", en Serrano Martín; E. y Gascón Pérez, J. (eds.), Poder, sociedad, religión y tolerancia en el mundo hispánico, de Fernando el Católico al siglo XVIII, Zaragoza, Institución Fernando el Católico, 2018, pp. 1241-1257.

Bonzon, A., L'esprit de clocher. Prêtres et paroisses dans le diocèse de Beauvais, 15351650, París, Éditions du Cerf, 1999.

Bravo Lozano, J., "Cura rico, cura pobre. Notas sobre rentas eclesiásticas en el Madrid de fines del siglo XVII", en Martínez Ruiz, E. y Suárez Grimón, V. (eds.), Iglesia y Sociedad en el Antiguo Régimen, I, Las Palmas de Gran Canaria, Universidad, 1994, pp. 129-139.

Brumont, F., "Le clergé diocésain dans la France moderne", Obradoiro de Historia Moderna, 22 (2013), pp. 231-248.

Bunes Ibarra, M. Á. de, "La Iglesia en la España de los Austrias: Una aproximación a las tendencias historiográficas", en Andrés-Gallego, J., (ed.), La Historia de la Iglesia en España y el mundo hispano, Murcia, Universidad Católica San Antonio de MurciaCátedra de Ciencias Sociales, Morales y Políticas, 2001, pp. 191-208.

Burgos Rincón, F. J., "Los libros privados del clero: La cultura del libro del clero barcelonés en el siglo XVIII", Manuscrits. Revista d'història moderna, 14 (1996), pp. 231-258.

Cabeza Rodríguez, A., "Estudio del clero diocesano en el Antiguo Régimen a través de los fondos documentales de las Audiencias Episcopales", Investigaciones Históricas. Época moderna y contemporánea, 11 (1991), pp. 35-51.

Candau Chacón, M. L., "Los libros de visita parroquiales como fuente en el estudio del clero rural a comienzos del siglo XVII", Historia Moderna. Actas de las II Jornadas de Metodología y Didáctica de la Historia, Cáceres, Universidad de Extremadura, 1983, pp. 435-442.

- Iglesia y sociedad en la campiña sevillana: la vicaría de Écija (1697-1723), Sevilla, 
Diputación Provincial, 1986.

- La carrera eclesiástica en el siglo XVIII. Modelos, cauces y formas de promoción en la Sevilla rural, Sevilla, Universidad, 1993a.

- Los delitos y las penas en el mundo eclesiástico sevillano del XVIII, Sevilla, Diputación Provincial, 1993b..

- El clero rural de Sevilla en el siglo XVIII, Sevilla, Caja Rural Provincial, 1994.

— "Familias y relevos en el mundo eclesiástico. El entorno rural de Sevilla, 1685-1785", en Casey, J. y Hernández Franco, J. (eds.), Familia, parentesco y linaje, Murcia, Universidad, 1997, pp. 277-291.

— "El clero secular hispalense a fines del Antiguo Régimen: los problemas de la vocación eclesiástica", en Bernardo Ares, J. M. de (ed.), El Hispanismo Anglonorteamericano. Aportaciones, problemas y perspectivas sobre Historia, Arte y Literatura españolas (siglos XVI-XVIII), I, Córdoba, Obra Social y Cultural Cajasur, 2001, pp. 309-324.

Carpintero Aguado, L., "La contribución del clero castellano a los servicios de Millones", Revista de historia moderna: Anales de la Universidad de Alicante, 15 (1996), pp. 271298.

Carpio Dueñas, J. B., La Tierra de Córdoba: el dominio jurisdiccional de la ciudad durante la baja Edad Media, Córdoba, Universidad, 2000.

Castro Pérez, C., "La institución parroquial a través de los registros contables del Señorío episcopal de la villa de Agüimes, 1500-1860", Anuario de historia de la Iglesia, 16 (2007), pp. 424-427.

Castro Pérez, C., Calvo Cruz, M. y Granado Suárez, S., "Análisis de una defunción en los siglos XVII-XVIII a través de las anotaciones contables que realizaba el colector parroquial", Tiempos modernos: Revista Electrónica de Historia Moderna, 15 (2007), pp.1-14.

Catalán Martínez, E., El precio del purgatorio. Los ingresos del clero vasco en la Edad Moderna, Bilbao, Universidad del País Vasco, 2000.

— "Parroquias y curas en el obispado de Calahorra y La Calzada (siglos XI-XVI)", Obradoiro de Historia Moderna, 22 (2013), pp. 35-62.

- "El clero rural vasco durante la Edad Moderna", en Porres Marijuán, R. (coord.), Entre el fervor y la violencia. Estudios sobre los vascos y la Iglesia (siglos XVI-XVIII), Bilbao, Universidad del País Vasco, 2015, pp. 17-56.

Colás Latorre, G., "La renta del clero rural aragonés a fines del Quinientos", en Martínez Ruiz, E. y Suárez Grimón, V. (eds.), Iglesia y Sociedad en el Antiguo Régimen, I, Las Palmas de Gran Canaria, Universidad, 1994, pp. 449-460.

Collelldemont Vives, E., "Inventari post mortem d'un rector català del S. XVIII", Pedralbes: Revista d'història moderna, 28 (2008), pp. 585-596.

Cortés Peña, A. L., Iglesia y cultura en la Andalucía Moderna. Tendencias de la investigación, estado de las cuestiones, Armilla (Granada) Proyecto Sur de Ediciones, 1995.

— "Conflictos jurisdiccionales entre la Iglesia y los poderes civiles en el siglo XVIII", en Cortés Peña, A. L. (ed.), Poder Civil, Iglesia y Sociedad en la Edad Moderna, Granada, Universidad, 2006, pp. 437-452.

Cortés Peña, A. L. y López-Guadalupe Muñoz, M. L., "Historiografía sobre la iglesia en Andalucía (Edad Moderna)", Tiempos modernos: Revista Electrónica de Historia Moderna, 20 (2010), pp. 1-44.

Cuenca Toribio, J. M., "La historiografía eclesiástica española contemporánea. Balance provisional a finales del siglo", Hispania sacra, 103 (1999), pp. 355-383.

Curiel Yarza, I., La parroquia en el País vasco-cantábrico durante la Baja Edad Media (c. 1350-1530): organización eclesiástica, poder señorial, territorio y sociedad, Bilbao, 
Universidad del País Vasco, 2009.

Díaz De Durana Ortiz De Urbina, J. R., "Patronatos, patronos, clérigos y parroquianos: los derechos de patronazgo sobre monasterios e iglesias como fuente de renta e instrumento de control y dominación de los parientes mayores guipuzcoanos (siglos XIV a XVI)", Hispania sacra, 102 (1998), pp. 467-508.

Díaz lbáñez, J., La organización institucional de la Iglesia en la Edad Media, Madrid, Arco, 1998.

- "Jurisdicción episcopal y violencia en el clero diocesano burgalés durante el siglo XV", Hispania sacra, 135 (2015), pp. 169-196.

Díaz Rodríguez, A. J., "Cabildos catedralicios y clero capitular en el Antiguo Régimen: estado de la cuestión", Revista de Historiografía, 13 (2010), pp. 82-99.

Domínguez Ortiz, A., La sociedad española en el siglo XVII, vol. II: El estamento eclesiástico, Granada, Universidad, 1992.

Fariña Jamardo, J., La parroquia rural en Galicia, Madrid, Instituto de Estudios de Administración Local, 1975.

Ferté, J., "La parrocchia rurale nel XVII secolo", en Russo, C. (a cura di), Societá, Chiesa e vita religiosa nell'Ancien Régime, Napoles, Guida Editori, 1976, pp. 3-62.

Flament, F., La Diócesis de Córdoba a través de las visitas ad limina (siglos XVI-XVIII), Córdoba, Cajasur, 2010.

Franco Rubio, G. A., "Datos sobre la iglesia madrileña del siglo XVIII: La Parroquia de Santa Cruz", Cuadernos de historia moderna y contemporánea, 2 (1981), pp. 127-146.

García Arancón, M. R., "El clero secular en Navarra a mediados del siglo XIII", Hispania sacra, 104 (1999), pp. 669-686.

García De Cortázar, J. A., La época medieval, Madrid, Alianza, 1974.

García De Valdeavellano, L., Curso de Historia de las Instituciones españolas, Madrid, Revista de Occidente, 1977.

García Hernán, E., "Visión acerca del estado actual en España de la historia de la Iglesia", Anuario de historia de la Iglesia, 16 (2007), pp. 281-308.

García Pardo, M., "La cultura clerical en el obispado de Jaén en la Baja Edad Media", Hispania sacra, 104 (1999), pp. 703-716.

Gascón Pérez, J., "Noticias sobre la participación del clero en la rebelión aragonesa de 1591", en Martínez Ruiz, E. y Suárez Grimón, V. (eds.), Iglesia y Sociedad en el Antiguo Régimen, Las Palmas de Gran Canaria, Universidad, 1994, pp. 611-621.

Gato Castaño, P., "La importancia del clero en la acción educativa según el obispo José Antoni de San Alberto (Charcas, 1786-1810)", Hispania sacra, 87 (1987), pp. 713-743.

Genicot, L., Comunidades rurales en el occidente medieval, Barcelona, Crítica, 1993.

Gil Bautista, R., "El clérigo Juan Félix Gijón de Astorga (Chillón, 1698-1760). Un hombre de su tiempo. Un hombre del tiempo", en Serrano Martín; E. y Gascón Pérez, J. (eds.), Poder, sociedad, religión y tolerancia en el mundo hispánico, de Fernando el Católico al siglo XVIII, Zaragoza, Institución Fernando el Católico, 2018, pp. 1433-1448.

Gómez Navarro, S., "Familia, estamento e institución: El clero secular en el reino de Córdoba a mediados del siglo XVIII. El caso de Lucena", Studia historica. Historia Moderna, 35 (2013), pp. 343-369.

González Cruz, D., "Actitudes del clero ante los conflictos bélicos de la monarquía hispánica durante el siglo XVIII", en Homenaje a Don Antonio Domínguez Ortiz, III, Granada, Universidad-Junta de Andalucía (Consejería de Innovación, Ciencia y Empresa), 2008, pp. 473-496.

González Polvillo, A. Iglesia y sociedad en la villa de Salteras durante el siglo XVI, Madrid, Deimos, 1994.

González Torrico, A. J., Aproximación histórica a la parroquia cordobesa de San Juan y 
Todos los Santos (La Trinidad) en la época moderna, Córdoba, Caja de Ahorros y Monte de Piedad, 2010.

Goujard, Ph., Un catholicisme bien tempéré La vie religieuse dans les paroisses rurales de Normandie, 1680-1789, París, Comité des Travaux Historiques et Scientifiques, 1996.

Greco, G., "Chiesa locale e clero secolare a Pisa nell'etá della Contrarriforma" en Mirri, M.

(a cura di), Ricerche di Storia Moderne, III, Pisa, Pacini, 1984, pp. 143-279.

— "Las parroquias en la Italia de la época moderna, siglos XV-XIX", Obradoiro de Historia Moderna, 22 (2013), pp. 1-34.

Herrera Mesa, P. P., Escritos Pastorales de los Obispos de Córdoba (1627-1857), Córdoba, Archivo Catedral de Córdoba, 2004.

Higueruela Del Pino, L., El clero de Toledo de 1800 a 1823, Madrid, Fundación Universitaria Española, 1979.

- La Iglesia en Castilla-La Mancha: la Diócesis de Toledo en la Edad Contemporánea (1776-1995), Toledo, Junta de Comunidades de Castilla-La Mancha, 2 vols. 2003.

Icaza Longoria, M. T., "La reorganización del territorio parroquial de la arquidiócesis de México durante la prelacía de Manuel Rubio y Salinas (1749-1765)", Hispania sacra, 128 (2011), pp. 501-518.

Irigoyen López, A., "Aproximación demográfica al clero secular de Murcia en el siglo XVII", Chronica Nova, 24 (1997a), pp. 171-188.

- "Análisis de los hogares eclesiásticos en Murcia durante el siglo XVII", en Chacón Jiménez, F.; Ferrer I Alòs, LI. (eds.), Familia, casa y trabajo, Murcia, Universidad, 1997b, pp.181-196.

- "Clero secular, familia y movilidad social: actores y directores (Murcia, siglo XVII)", en Chacón Jiménez, F. y Hernández Franco, J. (eds.), Familias, poderosos y oligarquías, Murcia, Universidad, 2001, pp. 131-152.

- "Bajo el manto de la Iglesia. Clero y familia en España durante la Edad Moderna", en Chacón Jiménez, F. y Hernández Franco, J. (eds.), Espacios sociales, universos familiares. La familia en la historiografía española. XXV aniversario del Seminario Familia y élite de poder en el Reino de Murcia. Siglos XV-XIX, Murcia, Universidad, 2007, pp. 245-269.

- "Los tratados de perfección sacerdotal y la construcción de la identidad social del clero en la España del siglo XVII", Hispania: Revista española de historia, 230 (2008), pp. 707-734.

- "Iglesia y movilidad social. Aproximación a los grupos familiares del clero en la diócesis de Cartagena durante la Edad Moderna", en Bravo Caro, J. J. y Sanz Sampelayo, J. (eds.), Población y grupos sociales en el Antiguo Régimen, II, Málaga, Universidad, 2009, pp. 851-859.

- "Carrera eclesiástica, servicio doméstico y curso de vida (Murcia, siglo XVIII)", Revista de historia moderna: Anales de la Universidad de Alicante, 34 (2016), pp. 279-295.

Lara Ramos, A., "Mentalidad y prácticas sociales: Conflictos civiles y eclesiásticos en el Guadix del XVIII", en Cortés Peña, A. L., López-Guadalupe Muñoz, M. L. y Lara Ramos, A. (eds.), Iglesia y Sociedad en el reino de Granada (ss. XVI-XVIII), Granada, Universidad-Diputación, 2003, pp. 341-355.

Larrea, M. Á. y Mieza, R. M., "Nota de acercamiento al clero secular rural del Señorío de Bizkaia en la Edad Moderna", Vasconia, 37 (2011), pp. 77-98.

Le Bras, G., "La pratique religieuse dans les villes et les campagnes, en Études de sociologie religieuse, París, Presses Universitaires de France, 1955, pp. 470-481.

Léonard, J. (dir.), Prêtres et pasteurs. Les clergés à l'ère des divisions confessionnelles (XVIe-XVIle siècles), Rennes, Presses Universitaires, 2016. 
Linage Conde, A., Las Visitas diocesanas a las Parroquias de Sepúlveda (1517-1851), El Escorial, Publicaciones del R.C.U. Escorial-Mª Cristina, 2017.

López, T., Diccionario Geográfico de Andalucía: Córdoba. (Edición de C. Segura Graíño), Córdoba, Diputación, 2008.

López Alsina, F., "La reforma eclesiástica: la generalización de un modelo parroquial renovado"., en Iglesia Duarte, J. I. de la (coord.), Los espacios de poder en la España medieval. XII Semana de Estudios Medievales, Logroño, Instituto de Estudios Riojanos, 2002, pp. 425-457.

López-Guadalupe Muñoz, M. L., "La diócesis de Granada en la visita ad limina de 1685", Chronica Nova, 20 (1992), pp. 361-386.

- "De clero y fieles en la diócesis de Granada a través de las visitas pastorales de la segunda mitad del siglo XVIII", Chronica Nova, 23 (1996), pp. 293-341.

— "El clero secular de la diócesis de Granada en 1527", Chronica Nova, 30 (2003-2004), pp. 645-680.

Loupès, Ph., La vie religieuse en France au XVIIle siècle, París, SEDES, 1993.

Luna Díaz, J. A., "La parroquia de Santa María Magdalena de Granada, un barrio en expansión hacia la vega durante el siglo XVI", Chronica Nova, 11 (1980), pp. 187-244.

Madoz, P., Diccionario Geográfico-Estadístico-Histórico de España y sus posesiones de Ultramar, Valladolid, Ámbito Ediciones, 1987.

Mantecón Movellán, T. A., "La capacidad del clero secular para apaciguar las disputas entre los campesinos montañeses del siglo XVIII", en Martínez Ruiz, E. y Suárez Grimón, V. (eds.), Iglesia y Sociedad en el Antiguo Régimen, Las Palmas de Gran Canaria, Universidad, 1994, pp. 149-156.

Martín Martín, J. L., "Beneficios y oficios del clero rural castellano (siglos XIII-XV)", Anuario de estudios medievales, 35/2 (2005), pp. 693-736.

Martín Riego, M., "Nivel moral del clero parroquial en la archidiócesis hispalense en la segunda mitad del siglo XVIII", Andalucía Moderna (I). Actas del II Congreso de Historia de Andalucía, Córdoba, Consejería de Cultura de la Junta de Andalucía-Obra Social y Cultural Cajasur, 1995, pp. 479-490.

- Los concursos a parroquias en la archidiócesis de Sevilla (1611-1926), Córdoba, Cajasur, 1999.

Martín Riego, M. y Ruiz Sánchez, J.-L., "Historiografía de la Edad Moderna y Contemporánea de la Iglesia de la Andalucía Occidental (1965-2007)", Anuario de Historia de la Iglesia Andaluza, I (2008), pp. 13-122.

Martínez Ruiz, E. (coord.), El peso de la Iglesia. Cuatro siglos de Órdenes Religiosas en España, Madrid, Actas, 2004.

Miranda Díaz, B., "Las parroquias de Carrión de los Céspedes y Castilleja del Campo, 1755-1831", Anuario de Historia de la Iglesia andaluza, 9 (2016), pp. 161-180.

Morán Corte, A., "El servicio doméstico en los hogares del clero asturiano. Una aproximación al caso ovetense a mediados del siglo XVIII", en Serrano Martín, E. y Gascón Pérez, J. (eds.), Poder, sociedad, religión y tolerancia en el mundo hispánico, de Fernando el Católico al siglo XVIII, Zaragoza, Institución Fernando el Católico, 2018, pp. 1549-1563.

Morgado García, A., Iglesia y sociedad en el Cádiz del siglo XVIII, Cádiz, Universidad, 1989.

- "El clero gaditano en el siglo XVIII", en Actas del Congreso Internacional sobre "Carlos III y la Ilustración", II: Economía y Sociedad, Madrid, Ministerio de Cultura, 1990, pp. 389-402.

— "El bajo clero secular de la diócesis e Perpiñán (Elna) en el siglo XVIII", Pedralbes: Revista d'història moderna, 11 (1991), pp. 137-154. 
— "La diócesis de Cádiz y el reformismo borbónico", en La Parra López, E. y Pradells Nadal, J. (eds.), Iglesia, Sociedad y Estado en España, Francia e Italia (ss. XVIII al XX), Alicante, Instituto de Cultura "Juan Gil-Albert"-Diputación Provincial, 1992, pp. 321330.

— "Las bases humanas y económicas del clero de la diócesis de Cádiz en la segunda mitad del siglo XVIII", en Andalucía Moderna (I). Actas del II Congreso de Historia de Andalucía, Córdoba, Consejería de Cultura de la Junta de Andalucía-Obra Social y Cultural Cajasur, 1995, pp. 491-501.

- El estamento eclesiástico y la vida espiritual en la diócesis de Cádiz en el siglo XVII, Cádiz, Universidad, 1996.

- Ser clérigo en la España del Antiguo Régimen, Cádiz, Universidad, 2000.

— "Dominguez Ortiz y el clero en la España moderna", Historia social, 47 (2003), pp. 29-51.

- "La Iglesia como factor de movilidad social: Las carreras eclesiásticas en la España del Antiguo Régimen", en Chacón Jiménez, F. y Monteiro, N.G. (eds.), Poder y movilidad social. Cortesanos, religiosos y oligarquías en la península Ibérica (siglos XV-XIX), Murcia, CSIC-Universidad, 2006, pp. 61-96.

— "El clero secular en la España Moderna: Un balance historiográfico", en Cortés Peña, A. L. y López-Guadalupe Muñoz, M. L. (eds.), La Iglesia española en la Edad Moderna. Balance y perspectivas, Madrid, Abada Editores, 2007a, pp. 39-73.

- "El clero en la España de los siglos XVI y XVII. Estado de la cuestión y últimas tendencias", Manuscrits. Revista d'història moderna, 25 (2007b), pp. 75-100.

- La diócesis de Cádiz: De Trento a la desamortización, Cádiz, Universidad, 2008.

- "Las carreras eclesiásticas en la Diócesis de Cádiz en el siglo XVII", en Soria Mesa, E. y Bravo Caro, J. J. (eds.), Las élites en la época Moderna: la monarquía española, IV: Cultura, Córdoba, Universidad, 2009, pp. 329-341.

— "Iglesia y familia en la España Moderna", Tiempos modernos: Revista Electrónica de Historia Moderna, 20 (2010), pp. 1-22.

— "Curas y parroquias en la diócesis de Cádiz (1700-1834)", Obradoiro de Historia Moderna, 22 (2013), pp. 207-230.

Nieto Cumplido, M. (coord.), Historia de las diócesis españolas, 8: Iglesias de Córdoba y Jaén, Madrid-Córdoba, BAC-Cajasur, 2003.

Nieto-Márquez Marín, P., "La 'Fábrica de la Iglesia' de la Villa de Adamuz. La economía de una Parroquia rural en la Diócesis de Córdoba en los siglos XVI-XVII", Studia cordubensia: revista de teología y ciencias religiosas de los centros académicos de la Diócesis de Córdoba, 2 (2009), pp. 143-180.

Olival, F. y Monteiro, N. G., "Movilidad social en las carreras eclesiásticas en Portugal (15001820)", en Chacón Jiménez, F. y Monteiro, N. G. (eds.), Poder y movilidad social. Cortesanos, religiosos y oligarquías en la península Ibérica (siglos XV-XIX), Murcia, CSIC-Universidad, 2006, pp. 97-125.

Palao Gil, F. J., "Conflictos entre el clero y el juzgado de amortización de Valencia ante la visita general de 1739", en Martínez Ruiz, E. y Suárez Grimón, V. (eds.), Iglesia y Sociedad en el Antiguo Régimen, I, Las Palmas de Gran Canaria, Universidad, 1994, pp. 523-531.

Peña Bocos, E., La atribución social del espacio en la Castilla Altomedieval. Una nueva aproximación al feudalismo peninsular, Santander, Universidad, 1995.

Pérez Baltasar, M. D., "Religión y sociedad en la Edad Moderna. Bibliografía", Cuadernos de Historia Moderna, 25 (2000), pp. 375-401.

Pérez González, S. M., "Clérigos en sociedad: El despliegue vital del clero secular andaluz en la Baja Edad Media”, Edad Media: revista de historia, 10 (2009), pp. 275-305. 
— "Los beneficios parroquiales: un acercamiento al estudio del clero secular", Hispania sacra, 130 (2012), pp. 497-523.

Pérez Mancilla, V. J., "La música en una parroquia española durante el siglo XVIII: Ia Iglesia de Nuestra Señora del Rosario de Salobreña (Granada)", Hispania sacra, 65/2 (2013), pp. 173-202.

Pérez Peinado, J. I., Matriz de las Siete Villas. Evolución histórica de la parroquia de El Salvador de Pedroche (Siglos IV al XX), Córdoba, Autor, 2013.

Pomar Rodil, P. J., "Música, espacio y función. Apuntes acerca de los órganos, tribunas y facistoles de la Colegiata y parroquias de Jerez de la Frontera", Anuario de Historia de la Iglesia andaluza, 10 (2017), pp. 231-248.

Porres Marijuán, R. (coord.), Entre el fervor y la violencia. Estudios sobre los vascos y la Iglesia (siglos XVI-XVIII), Bilbao, Universidad del País Vasco, 2015.

Pueyo Colomina, P., "El clero secular en la diócesis de Zaragoza: los libros de órdenes del arzobispo Añoz", en Martínez Ruiz, E. y Suárez Grimón, V. (eds.), Iglesia y Sociedad en el Antiguo Régimen, I, Las Palmas de Gran Canaria, Universidad, 1994, pp. 165176.

Puigvert I Solà, J. M., Església, territori i sociabilitat als segles XVII-XIX, Vic, Eumo-Universitat, 2001.

- "Los párrocos y las redes de sociabilidad parroquial en el mundo rural de la Cataluña moderna: Historiografía e Historia", Obradoiro de Historia Moderna, 22 (2013), pp. 167-206.

Regatillo, E. F., Derecho parroquial, Santander, Sal Terrae, 1965.

Restif, B., La révolution des paroisses: culture paroissiale et Réforme catholique en HauteBretagne aux XVe et XVIle siècles, Rennes, Presses Universitaires, 2006.

Rey Castelao, O., "Las economías eclesiásticas en la Edad Moderna. Un estado de la cuestión de la historiografía reciente (1994-2006)", en Cortés Peña, A. L. y LópezGuadalupe Muñoz, M. L. (eds.), La Iglesia española en la Edad Moderna. Balance y perspectivas, Madrid, Abada Editores, 2007, pp. 179-221.

Riera I Fortiana, E., "El estamento eclesiástico catalán en la guerra de la Independencia", Pedralbes. Revista d'història moderna, 2 (1982), pp. 211-236.

Rodríguez Cancho, M. A. y Blanco Carrasco, J. P., "Clero y realidad social en Extremadura en el siglo XVIII. Poder y privilegio", en Homenaje a Don Antonio Domínguez Ortiz, III, Granada, Universidad-Consejería de Innovación, Ciencia y Empresa, 2008, pp. 751768.

Rubio Pérez, L. M., "Párrocos, parroquias y concejos: El modelo parroquial leonés en el marco de las comunidades rurales y concejiles durante la Edad Moderna", Obradoiro de Historia Moderna, 22 (2013), pp. 129-166.

- "La parroquia como centro de sociabilidad en la vida y en la muerte. La comunidad parroquial, gestión y conflicto en el reino de León durante la Edad Moderna", en Serrano Martín; E. y Gascón Pérez, J. (eds.), Poder, sociedad, religión y tolerancia en el mundo hispánico, de Fernando el Católico al siglo XVIII, Zaragoza, Institución Fernando el Católico, 2018, pp. 1989-2001.

Rueda Fernández, J. C., "Los registros parroquiales en Catilla. Notas sobre su implantación, desarrollo y reglamentación en la ciudad y diócesis de Zamora (siglos XVI-XVII)", Studia historica. Historia Moderna, 8 (1990), pp. 7-37.

Ruiz Pérez, A., Demografía, sociedad, instituciones eclesiásticas y religiosidad en El Coronil durante los siglos XVI y XVII, S. I., Autor, 2007.

Saavedra, P., Sobrado, H. y Presedo, A., "La red parroquial y el clero rural en la Galicia de los siglos XVI-XIX: Resultados de una investigación en curso", Obradoiro de Historia 
Moderna, 22 (2013), pp. 93-128.

Sabatè i Bosch, J. M.: "Els 'estats de parròquia' i els llibres de 'compliment pasqual': bases metodològiques per l'estudi de la població", en Bravo Caro, J. J. y Sanz Sampelayo, J. (eds.), Población y grupos sociales en el Antiguo Régimen, II, Málaga, Universidad, 2009, pp. 1241-1252.

Sánchez González, R., "El clero rural del arzobispado de Toledo en el seiscientos", en Martínez Ruiz, E. y Suárez Grimón, V. (eds.), Iglesia y Sociedad en el Antiguo Régimen, Las Palmas de Gran Canaria, Universidad, 1994, pp. 187-195.

- "El clero rural del Arzobispado de Toledo en el seiscientos: distribución, formación y conducta", Hispania sacra, 94 (1994), pp. 427-447.

Sánchez Herrero, J., La diócesis del reino de León. Siglos XIV y XV, León, Centro de Estudios e Investigación "San Isidoro", 1978.

Sanz De La Higuera, J., "'Un capellán que sirve la mesa' y otros menesteres. Burgos a mediados del siglo XVIII", Studia historica. Historia moderna, 24 (2002), pp. 331-362.

— "Clérigos a la sombra de un pariente en el XVIII burgalés", Hispania sacra, 120 (2007), pp. 563-594.

— "La vestimenta del clero en el Burgos del XVIII", Revista de historia moderna: Anales de la Universidad de Alicante, 31 (2013), pp. 127-146.

Sanz Sancho, I., La Iglesia y el Obispado de Córdoba en la Baja Edad Media (1236-1426), I-II, Madrid, Universidad Complutense, 2 volúmenes, 1989.

- Geografía del Obispado de Córdoba en la Baja Edad Media, Madrid, Universidad Autónoma-Ediciones Polifemo, 1995.

Segado Gómez, L., "La parroquia de Villafranca de Córdoba. Una aportación a su historia a través de la visita pastoral de 1590. Preceptos de los visitadores a finales del siglo XVI", en Crónica de Córdoba y sus Pueblos, XXII, Córdoba, Ilustre Asociación Provincial Cordobesa de Cronistas Oficiales-Diputación de Córdoba, 2016, pp. 571-600.

Soria Mesa, E. y Díaz Rodríguez, A. J. (eds.), Iglesia, poder y fortuna. Clero y movilidad social en la España moderna, Granada, Comares, 2012.

Teruel Gregorio de Tejada, M., Vocabulario básico de la Historia de la Iglesia, Barcelona, Crítica, 1993.

Testón Núñez, I. y Santillana Pérez, M., "El clero cacereño durante los siglos XVI al XVIII: Comportamiento y mentalidad", en Historia Moderna. Actas de las II Jornadas de Metodología y Didáctica de la Historia, Cáceres, Universidad de Extremadura, 1983, pp. 463-472.

Tovar Pulido, R., "Formas de vida religiosa en Trujillo: Familia y organización del hogar en la casa del clérigo a finales de la época moderna", en Serrano Martín, E. y Gascón Pérez, J. (eds.), Poder, sociedad, religión y tolerancia en el mundo hispánico, de Fernando el Católico al siglo XVIII, Zaragoza, Institución Fernando el Católico, 2018, pp. 16831694.

Ucero I Ramón, J. S., "Consuetuts de la parroquia de l'Almoster a finals del segle XVIII", Pedralbes: Revista d'història moderna, 8/2 (1988a), pp. 485-496.

- "Procedimiento administrativo en las colaciones de los curatos durante el reinado de Carlos III", Pedralbes: Revista d'hstòria moderna, 8/2 (1988b), pp. 497-502.

Valenzuela García, C., "Vida cotidiana y mentalidad en el bajo clero secular. Montoro en el siglo XVIII", Ámbitos. Revista de Estudios de Ciencias Sociales y Humanidades, 19 (2008a), pp. 35-46.

- Una contribución a la historia de la Iglesia: El clero de Palma del Río (Córdoba) en el siglo XVIII, Sevilla, Saxoferrero-Cajasol, 2008b.

— "Familia y relaciones sociales en la España del Antiguo Régimen. El caso del bajo clero 
secular de Montoro en el siglo XVIII", en Bravo Caro, J. J. y Sanz Sampelayo, J. (eds.), Población y grupos sociales en el Antiguo Régimen, II, Málaga, Universidad, 2009, pp. 1307-1320.

Ventura Gracia, M., Las cofradías cordobesas del Santísimo Sacramento. El caso de Espejo en la Edad Moderna, Córdoba, Universidad-Cajasur, 2010.

- "La organistía de la parroquia de Espejo durante los siglos XVI-XIX: virtualidad y vicisitudes de una institución musical", en Crónica de Córdoba y sus pueblos, XVIII, Córdoba, Ilustre Asociación Provincial Cordobesa de Cronistas Oficiales-Diputación de Córdoba, 2012, pp. 265-289.

- "Las capellanías, unos mayorazgos 'a lo divino' en la Edad Moderna. Aportación a su estudio en el ámbito rural cordobés", Boletín de la Real Academia de Córdoba de Ciencias, Bellas Letras y Nobles Artes, 162 (2013), pp. 51-95.

— "La capilla de Música de la parroquia de Espejo: una institución eclesiástico-cultural entre el Antiguo y el Nuevo Régimen", en Crónica de Córdoba y sus pueblos, XXI, Córdoba, Ilustre Asociación Provincial Cordobesa de Cronistas Oficiales-Diputación de Córdoba, 2016a, pp. 477-490.

- Una contribución a la historia de las instituciones: La iglesia parroquial de la villa cordobesa de Espejo en el Antiguo Régimen, Córdoba, Universidad [recurso electrónico], 2016b.

- "Nueva aportación al estudio de las capellanías en la diócesis de Córdoba: El caso de la villa de Luque en el los siglos XVI y XVII", en Aranda Doncel, J., Cosano Moyano, J. y Escobar Camacho, J. M. (coords.), La Subbética cordobesa. Una visión histórica actual, Córdoba, Real Academia de Ciencias, Bellas Letras y Nobles Artes, 2017, pp. 277-337. 